\title{
Pyloric Stenosis as Cause of a Venous Hypertensive Syndrome Mimicing True Shaken Baby Syndrome
}

\section{David G Talbert*}

Institute of Reproductive and Developmental Biology, Imperial College School of Medicine, Queen Charlotte's Hospital, UK

\begin{abstract}
A syndrome of bleeding in the brain with retinopathy, but no external evidence of trauma, is known in infants. There is an association with excessive crying and feeding difficulties in this condition. This has led to the hypothesis that the injuries arise during violent shaking by an angry carer, causing the brain to rotate relative to the skull, (Shaken Baby Syndrome, SBS).

An alternative hypothesis, described here, (Dysphagic Infant Death Syndrome DIDS), is that injuries similar to those in SBS can result from venous hypertension during excessive coughing or vomiting. Such injuries occur "naturally" during paroxysms of coughing in Whooping Cough. High intra-abdominal pressure drives abdominal venous blood up into the head, rupturing intracranial veins and capillaries. This results in subdural haemorrhages, petechiae in skin, and Valsalva Retinopathy in the eyes. This article considers when the excessive intra-abdominal pressures are caused by violent vomiting and retching in pyloric stenosis.

Some DIDS additional features, not occurring in SBS, may give warning of impending intracranial catastrophe. Infant skull suture growth rate depends on local stretch induced in the underlying Dura Mater. This will be increased during venous hypertension, accelerating head growth rate analogous to the hydrocephalous mechanism. The prolonged inconsolable crying would be explained by Mallory-Weiss tears at the oesophageal-stomach junction during repeated vomiting. Edema resulting from local leakage from over-distended cerebral veins and capillaries may temporarily disable axon transmission, causing temporary loss of consciousness. Transient "spiking" fevers may be seen in this condition if the temperature limiter center in the hypothalamus is temporarily disabled by such flooding. (Brainstem tissue is drained by the vertebral vein system whose tortuous nature smoothes out pressure spikes. This provides some protection of breathing and cardiac mechanisms which may remain normal.)
\end{abstract}

It is concluded that, unlike SBS, preventative measures should be possible for DIDS.

Keywords: Megacephaly; Retinopathy; SBS; DIDS; Subdural bleeds; Pylorus; Venous Hypertension; Petechiae

\section{Introduction}

The SBS hypothesis arose out of attempts to explain the origin of a series of clinical features recognized as forming a syndrome. This syndrome produced intracranial haemorrhages without evidence of external injury to the head. It appeared that the only way such injuries could be produced was by rotational inertia, such as might occur during manual shaking of the infant. Another feature of this syndrome was some prior dysphagia. It had been noticed that:- "The infant may have a history of poor feeding, vomiting, lethargy, and/or irritability occurring for days or weeks prior to the time of initial health care contact". This was construed as a provoking factor that could cause some emotionally vulnerable carers to shake the infant. The syndrome became known as Shaken Baby Syndrome [1]. The concept of SBS has subsequently been modified, renamed, broadened etc but this initial definition, closest to the unexplained syndrome originally recognized, is referred to in this article as True Shaken Baby Syndrome.

An alternative link to dysphagia, proposed here, is a physiological mechanism, excessive venous pressure. Compression of abdominal contents by simultaneous contraction of abdominal and diaphragm muscles during violent vomiting or retching, such as occurs in pyloric stenosis, will force blood retrograde up the IVC-SVC into cerebral veins. The term Dysphagic Infant Death Syndrome, (DIDS), has previously been proposed for this mechanism. While True SBS is not predictable, recognition of factors associated with excessive retching or vomiting may give warning of a DIDS event, enabling timely investigation for such agents as pyloric stenosis to be carried out before serious damage occurs, or posthumously, for differential diagnosis from SBS.

\section{Pyloric Features and Function}

The ancient Greek anatomist Galen (129-216 AD) recognised the significance of a sphincteric section of the alimentary tube in sealing the lower end of the stomach. He named this sphincter the "Pylorus" meaning "Gatekeeper", because it retains food in the stomach for the initial chemical processes of digestion to be completed. It then allows boluses through into the intestine (duodenum) (Figure 1).

The stomach's chemical digestive processes are well documented but the mechanical function carried out by the pyloric canal, of reducing the chewed but still lumpy items of food to a pulp, is largely ignored in text books.

The canal operates independently of, but in close cooperation

*Corresponding author: David G Talbert, Institute of Reproductive and Developmental Biology, Imperial College School of Medicine, Queen Charlotte's Hospital, Du Cane Road, London W12 0NN, UK, E-mail: d.talbert@imperial.ac.uk

Received November 25, 2011; Accepted December 23, 2011; Published January 05, 2012

Citation: David G Talbert (2011) Pyloric Stenosis as Cause of a Venous Hypertensive Syndrome Mimicing True Shaken Baby Syndrome. J Trauma Treat 1:102. doi:10.4172/2167-1222.1000102

Copyright: @ 2011 David G Talbert, This is an open-access article distributed under the terms of the Creative Commons Attribution License, which permits unrestricted use, distribution, and reproduction in any medium, provided the original author and source are credited. 
with, the pyloric sphincter. The combined sphincter and canal was identified as a distinct organ of the stomach in 1674 by Thomas Willis, an anatomist after whom the "circle of Willis" in the brain's arterial supply is named. He recognised that in the pyloric canal wall the muscle thickness was considerably greater than anywhere else in the stomach and that its folds were organised parallel to the axis of the lumen, Figure 1. (Inset)

\section{Prenatal development}

The wall of the pylorus has a basic layer configuration similar to that of the preceding alimentary canal. From the lumen outwards are mucosa, submucosa, circular muscle, and longitudinal muscle fibres, Figure 2. Functionally, the pylorus is not a simple "gate" as its name implies. In the pylorus the two muscle layers are very much more developed. They appear at different stages in embryonic development. The circumferential system appears first when the embryo is at the 23$41 \mathrm{~mm}$ length stage. The longitudinal muscle does not develop until the 41-75 $\mathrm{mm}$ stage [2].

With further development two neural plexuses appear, the Myenteric Plexus of Auerbach between the two muscle layers, and the Sub-Mucosal Plexus of Meissner. These are quite complex, the ganglion density in the pyloric region is 10 times that in the middle third of the oesophagus [2]. The Auerbach plexus appears to have a coordinating function, particularly in the sphincter. Fibres from the longitudinal muscle layer extend into the sphincter and provide an active opening action i.e. the sphincter does not just open passively [2].

\section{Postnatal development and function}

In the newborn the canal is longer in proportion to the stomach and its wall thinner than in the adult canal [3]. In adult carnivores and humans the pylorus is shorter than in most other species [4]. During infancy the proportions of muscular wall thickness to muscular wall diameter change to mature values which enable higher pressures to be generated for similar wall tensions. While the first stages of digestion take place in the stomach the pyloric sphincter remains closed, sealing off the lower end of the stomach. Periodically it relaxes to allow a bolus of partly digested food to pass through into the Duodenum (intestine), (Figure 2).

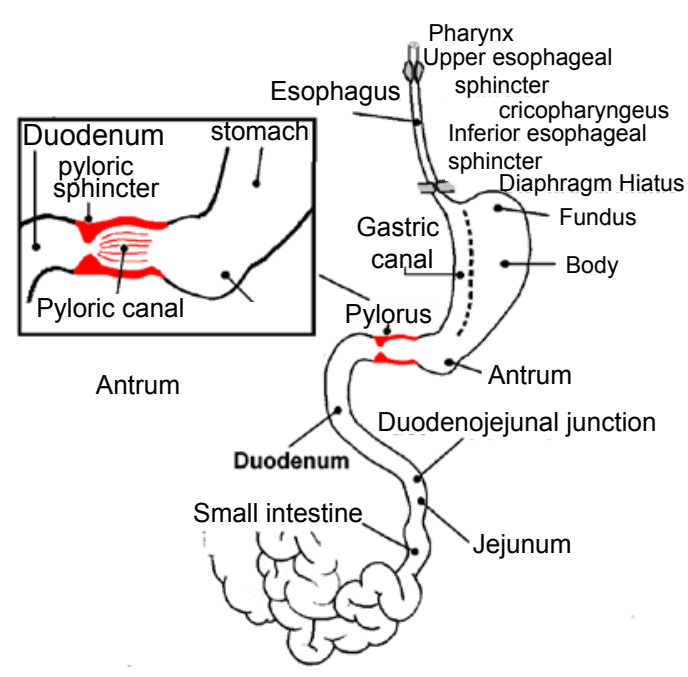

Figure 1: The upper digestive tract. Inset, pylorus components (canal and sphincter) and neighbours (stomach Antrum and intestine duodenum).

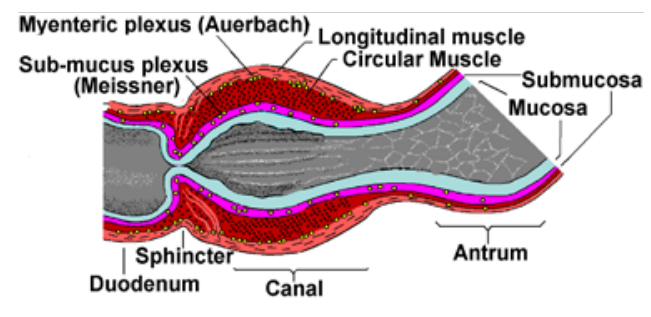

Figure 2: Pyloric physiology. Drawn from Annon 1956 (2).

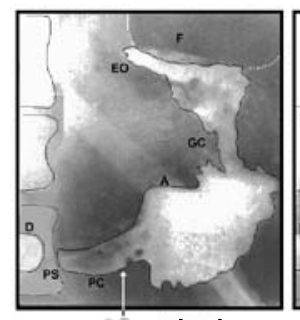

(a)

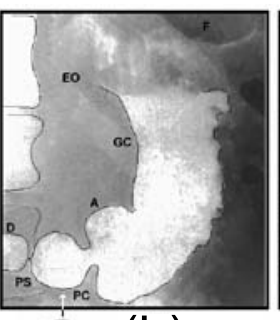

(b)

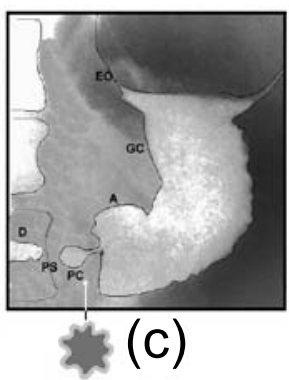

$A=$ Antrum, $D=$ Duodenum, Eo= Esophageal orifice, $F=$ Fundus, $\mathrm{Gc}=$ Gastric Channel, $\mathrm{PC}=$ Pyloric Channel, $\mathrm{Ps}=$ Pyloric Sphincter

Figure 3: Barium meal X-ray study of pyloric action in a young adult. (drawn from Millen (3)). Radiograph (a) was taken after a small swallow following an overnight fast. Barium lining the canal lumen surface from a previous "pump" produces a faint outline of pylorus canal folds. (b) Pyloric canal filling (diastole) after further swallows. (c) Canal contracting (systole) squirting a jet of chyme back into the stomach antrum.

The second function, mechanical lump reduction, led to the pylorus being described as the "mill" of the stomach, but perhaps the food "blender" is a better analogy. "Juices" secreted from the stomach wall partially dissolve the outer layer of food lumps, leaving a soft coating which must be removed before they can act on the next layer in. The pyloric canal does this by squirting jets of chyme back into chyme in the lowest part of the stomach (antrum). Figure 3 is based on a study by Millen [3]. In (a) a young human subject had just swallowed a small quantity of barium meal after an overnight fast. The stomach body and fundus (F) are empty and flattened but the gastric canal (GC) has sufficient structural rigidity to remain patent, and the meal outlines it. The meal has passed straight down the gastric canal into the antrum (A). The pyloric canal (PC) is still in its minimum volume configuration of longitudinal folds, see cross sections shown below. Some feed has been left in the outer creases of the pyloric canal lining giving shadowy outlines of the folds. In (b), after further swallows, the stomach has filled out and the pyloric canal is dilated into a spherical configuration. Millen refers to this as pyloric diastole because pyloric canal wall muscle tone is relaxed. At its distal end the pyloric sphincter remains firmly closed (no lumen visible $=$ no barium). At its proximal end the canal has narrowed, throwing the pyloric canal into a spherical shape. Pressure in a sphere is twice that in a tube for the same wall tension and radius so this maximises the pressure driving chyme in the following systole. In (c) the pyloric canal is in late systole, a jet of chyme has been ejected into the contents of the antrum (A). When this jet impinges on or near a lump the viscous forces strip off the softened outer layer giving digestive enzymes etc. access to the underlying surface. While an infant is on a liquid diet this pyloric "blender" action is not actually required but the pyloric muscle is converting to the adult configuration necessary for mechanical digestive efficiency after weaning. 


\section{Pyloric Stenosis and its Consequences}

\section{Pyloric stenosis}

Pyloric Stenosis means that the lumen of the alimentary canal has become too constricted. Moore and Dalley [5] describe two mechanisms of pyloric stenosis, hypertrophic growth and pylorospasm. Pylorospasm involves malfunction of otherwise normal musculature, causing it to remain in a contracted state. It is not considered further here. Hypertrophic pyloric stenosis involves the disproportionate thickening of the muscle in the pylorus wall and this is the case considered in this article. It is detected in approximately 1 of every 150 male infants and 1 of every 750 female infants [5]. Stenosis appears to be detected most often between 2 and 12 weeks of age, usually during or after the third week of life, but can be present at birth [6].

If the wall muscle becomes too thick too soon, or its diameter fails to increase appropriately, the lumen becomes too narrow. Increased effort is then required to drive chyme through the pyloric canal and sphincter into the duodenum, eventually inducing retching and vomiting. The infant may exhibit normal weight gain, but the abdominal pressures involved in retching or vomiting will also be applied to venous blood in the abdomen. Retching may cause "silent" venous hypertension before excessive vomiting becomes noticeable. This form of stenosis is not an all or nothing condition, it is a dynamic imbalance between muscle wall diametric and thickness growth rates.

\section{Transient Venous Hypertension; the Link between Abdominal Pressure and Head Haemorrhages}

Transient Cerebral Venous Hypertension (TCVH) is the fundamental mechanism linking the high intra-abdominal pressures occurring in paroxysmal coughing, retching or vomiting to injuries and bleeding in the head and eyes of infants. This occurs naturally in Whooping Cough (Bordetella pertussis). Before effective vaccination was devised injuries caused by venous hypertension were well understood. Morse [7], in his Textbook of Medicine describes Whooping Cough thus:-

In a typical paroxysm there is a series of 15 to 20 short coughs of increasing intensity, and then with a deep inspiration the air is drawn into the lungs, making the whoop. A tenacious plug is usually expelled, vomiting frequently follows the the spasmodic episode. Paroxysms are accompanied by signs of increased venous pressure. The conjunctivae are deeply engorged, there is periorbital edema, and petechial hemorrhages, particularly about the forehead, as well as epistaxis are common. Central nervous system changes can result from cerebral anoxia or hemorrhages consequent to the elevated venous pressure

McKendrick [8] details these internal injuries as:

Mechanical complications occur solely in the paroxysmal stages as a result of increased pressure in the thorax, abdomen or skull. Bleeding may occur from any surface or into the brain but the commonest results of rupture of blood vessels are epistaxis, subconconjunctival haemorrhage, and petechiae in the skin over the neck and upper chest. Haemoptysis, retinal detachment, and bleeding from the ears have all occurred. Herniae or rectal prolapse may appear.

Mattle et al. [9] investigated fainting in cough syncope in adults using transcranial Doppler sonography of the middle cerebral artery flow velocities. They concluded that during prolonged coughing raised intra-thoracic and intra-abdominal pressures were transmitted via the great veins to the intracranial compartment Hinchey et al. [10] studying cerebral white matter with $T_{2}$ weighted MRI, found myelinatedfibre tracts in a cellular matrix of glial cells, arterioles, and capillaries susceptible to vasogenic edema. They recognized a syndrome of headache, decreased alertness, altered mental functioning, seizures, and cortical visual loss. They attributed this to capillary leakage and acute disruption of the blood brain barrier under excessive pressure. They described this phenomenon as "transient edema" since in its milder forms recovery usually occurs. They say the mechanism is probably a capillary leak syndrome related to hypertension and fluid retention. Such a mechanism is the subject of this article, the excessive venous pressure being due to violent coughing, retching or vomiting $[11,12]$ In keeping with this postulation of a dysphagic origin of this venous hypertension hypothesis it is referred to here as Dysphagic Infant Death Syndrome, DIDS. In fact the infant itself may not die, but areas of brain death are to be expected.

\section{Clinical Manifestations}

The case histories of four infants (A, D, J and K.) formed the basis of this study. The medical histories of infants J [13] and A [12] have previously been reported. K. and D. had proven pyloric stenosis and are described here. Infant K's pyloric stenosis was not discovered until 6 weeks after the Event for which the carer was jailed. Furthermore, medical personnel in the PICU, and the Child Protection Team, were unaware of his previous medical history and so were uninfluenced by it. They believed they were treating a "previously healthy" 5 month old infant. This infant's history therefore documents a "natural history" of the progression of DIDS related to pyloric stenosis.

The time chart, Figure 4 shows the sequence of health problems that K. developed before and after the Event that led to arrest of his carer. Not all these problems will necessarily be present in all DIDS cases, not least because jugular vein valves which may give some protection vary in efficiency or may even be ineffective in the normal population [14].

Each of these problems was individually diagnosed and treatment attempted, but hindsight knowledge of his pyloric stenosis shows them to be unified as aspects of DIDS. In the following the various aspects are introduced in the order in which they were first reported. (Most continued subsequently)

\section{Excessive crying (infant D, 2 wks)}

These children had histories of inconsolable crying. Infant D. started extended (several hours duration) inconsolable crying episodes at two weeks old. After one prolonged screaming fit; he was taken to his physician who recommended changing his formula. At 20 days (3wks) D. was reported to have had a fussy episode lasting for $4 \mathrm{hrs}$. He continued with such episodes which his physician then attributed to colic. At his regular check-up at 5.5 wks growth was assessed to be normal but he was recorded as still suffering from colic. At $10 \mathrm{wks}$ his pyloric stenosis was diagnosed by ultrasound and confirmed at corrective surgery.

Forceful retching or vomiting can lead to tears at the junction of the esophagus and stomach. When these tears are limited to the inner lining, they are called Mallory-Weiss tears "Any condition that leads to violent and lengthy bouts of coughing or vomiting can cause these tears" [15]. Clearly, such trauma would be painful and explain the continuous inconsolable crying. Two weeks old may seem early for complications related to pyloric stenosis to appear, but Demian et al [6] found $5.8 \%$ of infants requiring surgery presented between 2 days and 2 weeks of 


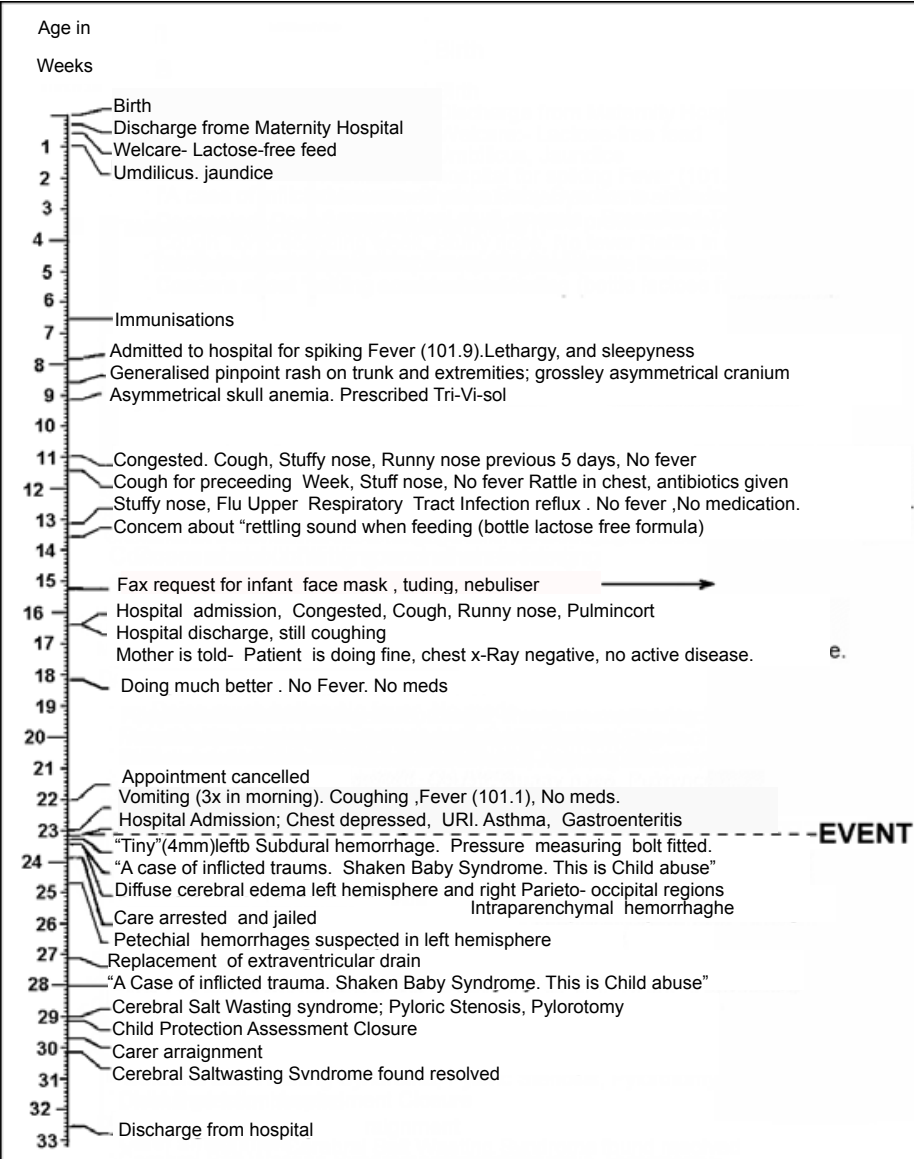

TIME CHART OF SIGNIFICANT EVENTS
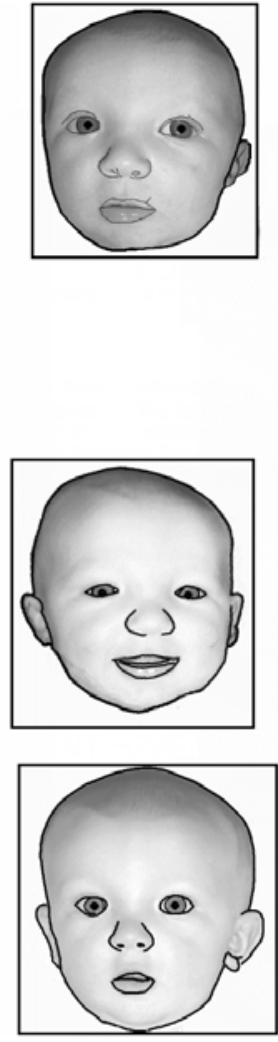

Figure 4: Time Chart of significant events. The head images show progressive changes in cranial shape. They were drawn from photographs by tracing the scalp outline seen through the hair and then drawing the outline as if the head had been shaved.

life. They describe this group as suffering from Early Pyloric Stenosis (EPS). Infant D appears to be an example of such developmental defect showing that DIDS due to pyloric stenosis would probably have no lower age limit

\section{Axon pulse conduction failure; lethargy, sleepiness and blank stares (3.5 wk)}

Blank Staring Episodes were observed and photographed by the mother of A (Figure 5).

Infant A. might be playing, then abruptly stop, staring ahead, completely unreactive to any stimulus. She would remain in this state for several minutes, then suddenly "wake up" and continue playing where she had left off. This is remarkably similar to Transient Global Amnesia (TGA) which predominantly affects people older than 50 years. It is defined by Schreiber et al. [16] as a benign condition characterized by sudden amnesia of less than 24 hours without any further focal neurological deficit Their postulated mechanism was thought to occur through involuntary Valsalva-like maneuvers In TGA this has been described as the trigger [17], but in DIDS these are considered causative agents. Ultrasound studies of flow through internal jugular veins of adult patients presenting with TGA have showed a significantly higher prevalence of retrograde internal jugular vein (IJV) blood flow, attributed to IJV incompetence [17] Jugular vein valves are known to be weak, even virtually absent in some individuals [14]. The close parallel between TGA in adults and DIDS in infants suggests that DIDS is effectively an infantile form of TGA. In adult TGA venous/capillary dilation is opposed immediately by rise in intracranial pressure, the Monro-Kellie doctrine [18]. However DIDS takes place

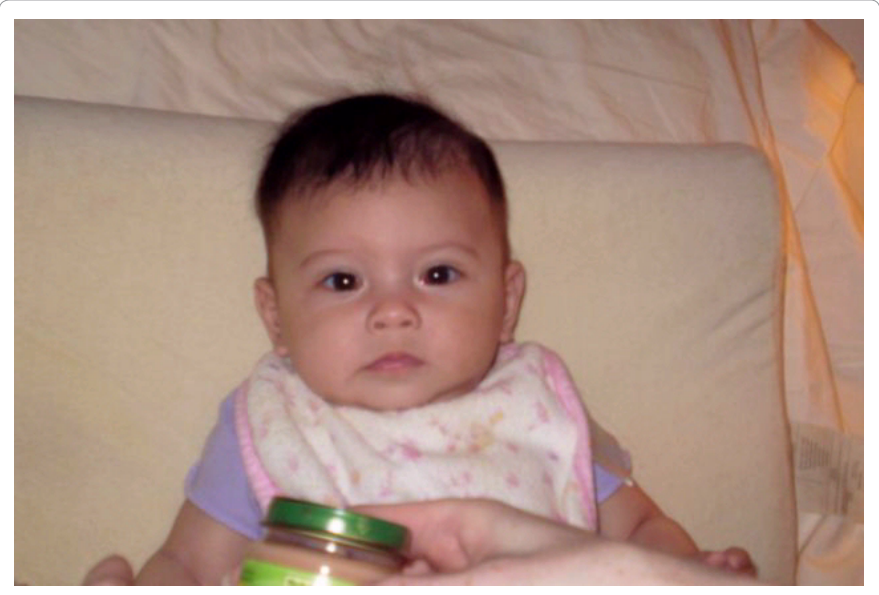

Figure 5: Blank stares. Infant A Completely unreactive to external events but continued normal breathing and colour. 
in an infant "elastic" skull where the Monro-Kellie doctrine does not apply. The infant skull will "give way" allowing venous/capillary dilation which may cause immediate catastrophic vascular damage, or only temporary "leakage" through the blood/brain barrier In both TGA and DIDS local edema will result from water expressed through capillary walls. In DIDS these walls will be transiently stretched, increasing their permeability. In the DIDS cases considered here the severity appears to have built up progressively producing reversible warning signs.

This local transient edema may disable Action Potential (Spike) production and transmission in axons, so disabling cerebral function. Information is transferred along an axon by successive brief opening of channels through its membrane. These cause electrical signals referred to as action potentials or spikes, which travel along the axon away from the neuron body. These channels allow ions to move through the membrane but they don't push them. They are selective in the sense that only their particular ion will fit in the channel, but the flow rate and direction depend on the concentration gradient across the membrane. Embedded in cell membranes are pumps removing $\mathrm{Na}^{+}$ions from cell interiors in exchange for bringing in $\mathrm{K}^{+}$ions from outside. These ions always leak back to some degree and the actual resting trans-membrane potential depends on the balance of these ionic flows. Normally the concentration of $\mathrm{Na}+$ ions surrounding cells is very much higher than that inside $(140 \mathrm{mEq} / \mathrm{L}$ c.f. $10 \mathrm{mEq} / \mathrm{L})$ [19] so when the $\mathrm{Na}^{+}$channels open there is an inrush of $\mathrm{Na}^{+}$which raises the potential inside the cell from $-70 \mathrm{mv}$ to $+40 \mathrm{mV}$ [20], forming the leading edge the action potential "Spike". But if the $\mathrm{Na}^{+}$outside has largely been swept away by water forced out of a nearby capillary there is no concentration gradient to produce the inrush and no spike will occur until the external $\mathrm{Na}^{+}$ concentration rebuilds.

The concentration ratio of $\mathrm{K}^{+}$Ions is the converse, $150 \mathrm{mEq} / \mathrm{L}$ inside and $5 \mathrm{mEq} / \mathrm{L}$ outside. The cell resting potential is very sensitive to changes in external $\mathrm{E}^{+}$concentration. Leakage of $\mathrm{K}^{+}$ions through capillary endothelial cell walls during transient venous hypertension may mean that the water washing around the axon is actually a dilute solution of $\mathrm{K}^{+}$ions which will add to the inhibition of spike potential generation. In general this will be only local to vulnerable capillaries and once the excess water has diffused away normal impulse transmission will return. However, while impulse transmission is disabled in critical neuron axons, cerebral function is disabled rendering the infant unconscious. No damage to neurons need be involved; it is merely an interruption of function which will return as soon as the transmembrane ionic balance returns. Hence the expressionless stare, lethargy, and sleepiness.

\section{"Spiking" fevers}

Brief fevers have been reported in these infants At 7 weeks infant $\mathrm{K}$ was taken to hospital suffering from fever $\left(101.9^{\circ} \mathrm{F}\right)$, and a week later he was admitted. The hospital notes record that "He was seen in this emergency department yesterday because of fever. When he went to Dr's office he had a history that he had been sleeping a lot more than usual, was lethargic. He was spiking fevers, and for that reason he was sent here for further management" Similarly at 20.5 weeks he is recorded as vomiting 3 times, coughing, and running a fever of $101.0^{\circ} \mathrm{F}$, yet at examination later in the day his temperature was $97.6^{\circ} \mathrm{F}$.

The fevers were described as "spiking" because they arose and ended abruptly. This was diagnosed as an infection but no infective agent was found. "Transient edema" [9] resulting from transient cerebral venous hypertension (TCVH) episodes, (driven by his pyloric stenosis) provides an explanation for these spiking temperatures, lethargy, and sleepiness. A centre in the brain at the base of the cerebrum (anterior hypothalamus), acts as a top temperature limiter [21]. If transient edema temporarily disabled this centre, and the heat generated by his current metabolic activity had exceeded his current passive heat loss, his temperature would have been free to drift up. Following such a hypertensive episode the excess water (edema) would slowly drain away, i.e. interruption is transient. Eventually the hypothalamus would "wake up" and resume function. His temperature would then rapidly return to normal, producing the characteristic "spiking" fevers seen in these subjects. The brain stem somatic control systems for heart rate, breathing etc are supplied and drained by the vertebral vasculature, whose tortuous nature smoothes out sudden changes. Thus the brain stem may continue to function normally.

\section{Petechiae and Subdural hemorrhage, bruising etc ( 8.5 wks)}

Petechiae are described by Lawrence Gibson [22] of the Mayo Clinic as "pinpoint-sized red dots under the surface of the skin. The dots are red because they contain blood that has leaked from tiny blood vessels (capillaries) into the skin". A common cause of petechiae is low platelet count (thrombocytopenia) in which leakage occurs at normal capillary pressure through weakened walls, but petechiae also result from high capillary lumen pressure in normal capillaries. It used to be thought that conjunctival and facial petechiae were hallmarks of asphyxial deaths, but in 2000 Ely and Hirsch [23] reviewed all the literature and concluded that there was no connection with asphyxia. Petechial "pathogenesis is related to the combined effect of increased cephalic venous pressure and hypoxic damage to endothelial cells."

Capillary failure under lumen hypertension was investigated by West et al. [24] who studied the endothelium of lung alveolar capillaries with electron microscopic techniques. They found that as pressure was raised failure occurred in three stages. The first involved rupture of the tight junctions between adjacent endothelial cells. The basement membranes remained intact, but as these are inherently porous the vessel walls became permeable to small molecules. The next stage was formation of pressure sensitive pores. These were minor tears in the basement membranes which, when stretched further open at higher pressures, allowed larger molecules to pass, but reverted to blocking them again when the pressure was lowered. Up to this stage, affected capillaries and veins might appear normal by light microscopy, since no erythrocytes had escaped. However, in the brain these initial leakage stages, (inter-endothelial gap porosity and stretched pore) would be sufficient to disrupt the blood brain barrier. Finally West et al found that the walls ruptured sufficiently for erythrocytes to be expelled through them. When this happens in the skin it shows as pinpoint red or purple dots, petechiae, forming a rash (Figure 6).

Thus it is not necessary to postulate hypoxic damage to endothelial cells [23], though that may occur subsequently. The venous hypertension is sufficient itself to disrupt cerebral function. Currently it is thought that "The most common cause of petechiae is through physical trauma such as a hard bout of coughing, vomiting, or crying, which can result in facial petechiae, especially around the eyes. Petechiae in this instance are completely harmless and usually disappear within a few days" [25].

Although petechiae in the skin may be harmless in themselves their occurrence indicates that venous pressure has recently been very high.

At 8.5 months during hospital investigation of spiking fevers 


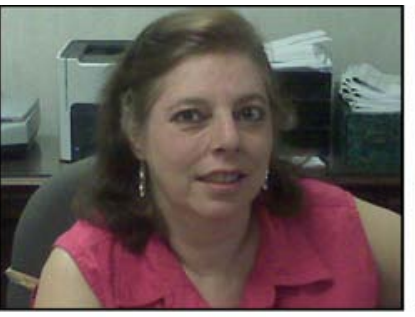

(a)

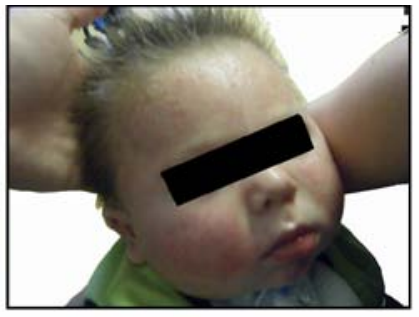

(b)
Figure 6: Petechiae. Photograph (a) was taken a few days after this person had had an evening of frequent vomiting. Compare the colour of her face with that of her arms. Photo (b) is of infant $\mathrm{D}$. shortly after an event.

for which no infective agent was found, K's contemporary hospital notes comment that he had "Generalised pinpoint rash on trunk and extremities. Skin gets mottled pink appearance." Similarly, at 22 wks (6 days before his Event), "little red splotches" were seen on K's head.

Veins also are vulnerable. Although their walls are more substantial than those of capillaries they are subject to greater tension. The tension in the wall of a tube follows the Law of Laplace [26].

\section{Tension $=$ Pressure $\mathrm{x}$ Radius}

Veins connecting the cortex to the cranial sinuses have radiuses many times greater than those of capillaries, so their walls have to withstand correspondingly higher tensions for the same lumen pressure. This may lead subdural hemorrhages [11].

Erythrocyte leakage through damaged capillary walls will be expected to produce similar skin discolourisation whether due to venous hypertension or bruising impact. Patches of petechiae overlying ribs were also seen on infants $\mathrm{A}$. and D see Figure 8. It is important that some means be found to distinguish between them for legal purposes.

\section{Macrocephally (9 wks)}

Water may accumulate from edema generated during transient cerebral venous hypertension, and it is well known that if cerebrospinal fluid is overproduced, or its outflow is obstructed, cranial growth becomes excessive (Hydrocephalus). It is commonly assumed that the skull is simply "stretched" by the excessive CSF volume, but actually skull growth is regulated to respond to the increased pressure. Those interested in the details of this process are referred to the excellent review article by Opperman [27].

The cranium starts in the embryo as a mesenchyme derived membranous half "balloon" lined with the dura mater [28]. The dura mater senses the tension and adjusts growth rate of the cranial membrane. Ossification centres develop within this membrane, typically at the positions of the centre of future skull bones. Ossification then spreads outwards from these centres until these bone plates approach each other. The remaining spaces between these intramembranous bones are designated "sutures". It is necessary to maintain these boundary regions patent or else the bones unite and skull growth is largely arrested, a condition known as craniosynostosis. In the mouse it has been shown that if the dura is stripped off the cranial membrane the intramembraneous bones develop abnormally and unite prematurely [28] Dura under ossified membrane is no longer subject to stretch, but under sutures it is stretched and responds by diffusing signalling material into the cranial membrane which inhibits osteogenesis and enhances chondrogenesis. This maintains sutures in their plastic state, capable of allowing the nascent skull bones to grow apart, enlarging the cranium. Tholpady et al. [29] maintained posterior intrafrontal sutures of the rat in vitro at a tension of $3 \mathrm{mN}$ for 30 minutes per day and found that they remained patent after 14 days whereas those maintained under no tension had fused. This shows that the osteogenesis inhibition and chondrogenesis augmentation signalling materials remained active after removal of the stress, preserving suture function. Thus the continuous stretch in hydrocephalus and the intermittent but repeated stretch in DIDS would be expected to result in similar excessive cranial growth.

During his hospitalization at 8 wks it was commented that K. had an odd-shaped cranium, asymmetrical, being flattened on the right side (Figure 4 upper image) Dilation of capillaries and veins, and transient oedema would cause temporary local increases in brain volume and the sutures would grow to match this temporarily increased brain volume, (see above). Brain expansion would not necessarily be uniform so neither would be skull growth, hence the deformity noted at $8 \mathrm{wks}$ and 15 wks in Figure 4 . Subsequently suture stretching seems to have become more general, because comments by onlookers related to a large head rather than asymmetry ( $23 \mathrm{wks})$. His head became disproportionately large and heavy. He had poor muscle control over it and his head would flop back as his position was changed while he was being held. Similar difficulties with head control have been previously reported in infants $\mathrm{J}[13]$ and $\mathrm{A}[12]$.

Plotting measurements made at pediatrician check-up visits gives valuable insight into pre-event history (Figure 7).

Infant D's head circumference grew normally until suddenly, around 11 weeks (just before the Event), growth rate increased to roughly 5 times previous rate. In 4 days it enlarged as much as would have taken just under 3 weeks if it had continued at its previous rate. A similar acceleration occurred in infant A later in infancy, at just over 4 months. In infant $\mathrm{K}$ there appears to have been an episode of pyloric narrowing between 2 and 3 months that resolved spontaneously (red). Both infant total length and head circumference ceased to increase, but weight increase accelerated. This cessation of growth is characteristic of pyloric blockage, and the weight increase with resultant edema.
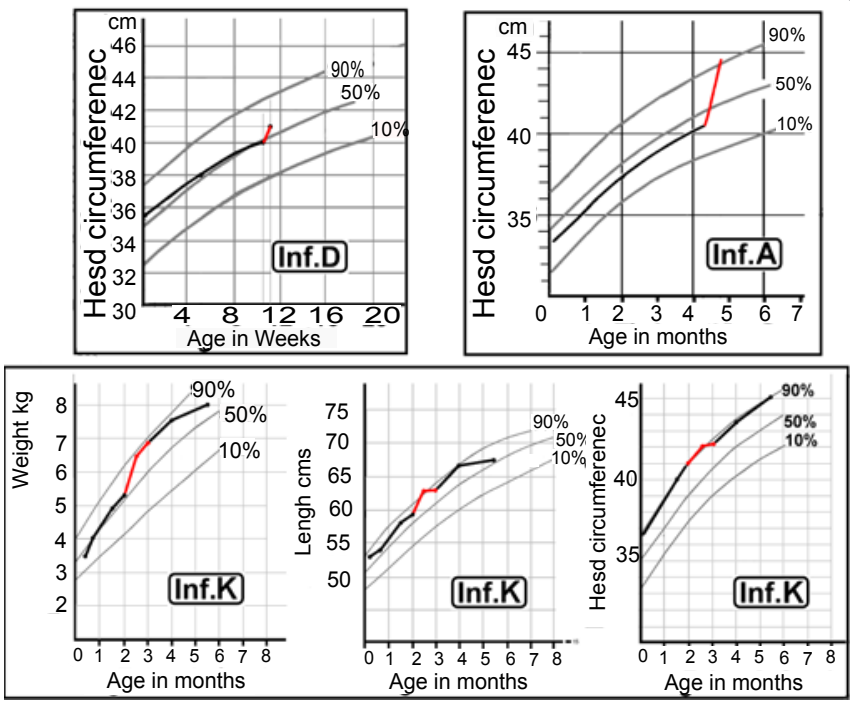

Figure 7: Plots of measurements made at pediatrician check-up visits. 


\section{THE ANODERM AND PERI-ANAL REDNESS}

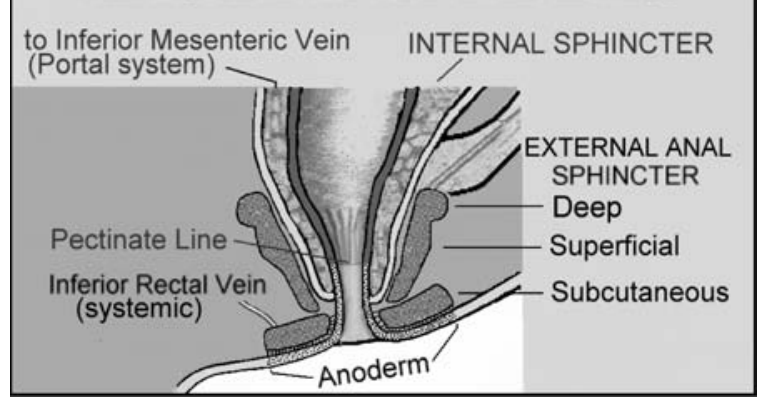

Figure 8: The anal sphincter system and its venous connections. The skin lining the anal outlet (anoderm) continues externally over the lowest (subcutaneous) section of muscle, with which it shares venous drainage.

The spontaneous recovery suggests further growth of canal diameter resolved the pyloric wall muscle thickness/diameter mismatch.

\section{Cough and "Runny Nose"}

Though hardly diagnostic these are consistent with sudden unexpected vomit spilling past the soft palette into the nose and under the epiglottis setting up irritation which caused the unexplained persistent cough and stuffy nose.

\section{K's Event}

Returning home from Daycare on the day of the Event involved a 30 to 40 minute car drive through bush fire smoke. When $\mathrm{K}$. arrived home he was breathing with difficulty and his family noticed his breathing was accompanied by a musical sound. This is known to anaesthetists as "Stridor". Mather [30] explains "Stridor is the musical or squeaky sound when air traverses the partially obstructed upper airway. Stridor in inspiration is due to laryngeal obstruction, whereas expiratory stridor largely originates below the larynx". This indicates that K's airway was severely constricted, either in direct response to the smoke, or as a result of inhalation of reflux during coughs. He was taken to the local hospital.

\section{Hospital records following the event $(23+$ weeks $)$}

On arrival at the local hospital CT scanning showed K. had a left subdural haematoma with questionable older right subdural haematoma. He was responding to painful stimuli so he was sedated, intubated with a 4-0 uncuffed ET tube and transferred to the Pediatric ICU of a larger hospital for further care and management.

Their admission records state: "The patient is intubated and sedated. His pupils are $3 \mathrm{~mm}$ nonreactive over a period of 30 minutes to an hour. He gradually woke up some and began to move all of his extremities with good strength. However, he did not open his eyes and was not interactive. He had no evidence of bruising. The patient was in a cervical collar. His reflexes were symmetric and appropriate. His muscle tone and strength are good and normal." So, at admission to the PICU both sides of his brain were acting appropriately. The local Child Protection Team Final Case Summary Report, published the next day stated K. had sustained a left subdural haematoma but there were no externally visible signs on K. There was pressure on K.'s brain and the area around his anus was extremely red but there was no tearing. However, in the following 11days in hospital successive CT scans showed new parenchymal brain hemorrhages, and on the $12^{\text {th }}$ day it was noted that "the baby has been noticed not to move his right side of his body as much as his left".

Thus there was evidence of a subdural haematoma, previous to the Event, and of recurrent new bleeds while in hospital associated with loss of right side voluntary movement.

\section{Peri-anal redness and Egregious Assault (Aggravated SBS)}

Peri-anal redness formed the basis for increasing the seriousness of the offence from SBS to Aggravated SBS. Since the redness appeared to be unrelated to shaking, and as no other cause seemed to exist, it was assumed to be the result of some form of imposed trauma. Venous hypertension related to pyloric stenosis provides an alternative physiological explanation.

The External Anal Sphincter system, Figure 8 has three major components, the Deep which surrounds the lower end of the internal anal sphincter, the Superficial, and the Subcutaneous. The system is under voluntary control and its blood supply is from the systemic system. The "subcutaneous" division of the external sphincter gets its name from the fact that it lies just under the skin surrounding the anus outlet (anoderm). The anoderm and muscle of subcutaneous division of the external anal sphincter share drainage by the inferior rectal vein $[31,32]$ whereas the skin surrounding the anoderm has normal integument supplies from a fine network of arterioles and venules.

When violent abdominal contractions occurred during paroxysmal coughing, retching or vomiting, flow would have reversed along inferior rectal veins down into the subcutaneous external anal sphincter muscle and the anoderm, producing brief surges of very high venous pressure. Some capillaries and venules in the anoderm would immediately have had their walls damaged, producing a "rash" of red petechiae. In contrast, the skin surrounding the anoderm, being drained by a network of anastomosing fine veins, would require appreciable time to fill to a pressure sufficient to cause local wall rupture. It would remain a normal colour. Such peri-anal redness may well occur in other contexts and be dismissed as diaper (nappy) rash but in this context of assumed SBS it was assumed to be imposed trauma.

\section{Surgical relief of pyloric stenosis, (Ramsteadt's procedure)}

At 10 weeks infant $\mathrm{D}$ vomited violently (projectile) and his physician directed the parents to take him to the local ER. On ultrasound scan he was found to be suffering from Pyloric Stenosis and he was operated on to relieve this obstruction. This involves cutting along the pylorus to the depth of the muscle layers (Figure 2) but leaving the mucosa intact, Ramsteadt's procedure [33]. Contraction of the circular muscle fibers then only distorts the mucosal wall of the canal leaving a passage for chyme to leak through to the duodenum. While this may temporarily weaken the "blender" action, wall configuration appears to return to the normal range within 12 weeks [34 ]

Following this surgery $\mathrm{D}$ developed spiking fevers surging to $103^{\circ} \mathrm{F}$ and then dropping abruptly. Two days post surgery he was discharged with a diagnosis of viral infection and parents instructed to give him Tylenol. Five days post surgery, at a follow up visit to his paediatrician, he was considered to be doing well, but continuing to be in some pain and there was inflammation at the incision site. A few hours later he suffered respiratory arrest, for which the father performed CPR. On arrival at the hospital he was unresponsive and taking breaths once or twice a minute, a known terminal breathing pattern. Subsequently he was found to have bilateral retinal haemorrhages and acute and chronic intracranial bleeds, including subdural bleeds. Approximately 3 months 
later D. was diagnosed as having been abused by SBS, the father was arrested, and a 2 year old sibling taken into care.

DIDS would offer a different explanation. Either the operation was unsuccessful, or the inflammation seen at the incision site was the surface manifestation of infection at the operative site, causing swelling that had narrowed the pylorus. The consequential cerebral venous hypertension would then have been sufficient to disable the hypothalamic temperature limiter, allowing the spiking fevers to occur. Thus DIDS would indicate that inflammation at the operative site is not trivial in Ramsteadt's procedure since it may lead to venous hypertension injuries.

\section{Apparent chest bruising}

The IVC and SVC return blood to the heart's right atrium. This feeds the the right ventricle which pumps blood into the pulmonary arteries. If IVC/SVC pressure exceeds pulmonary artery pressure the right atrium becomes a through path for blood to enter the pulmonary arterial system. Rib intercostal vessels run close to upper and lower edges of ribs (Figure 9A).

If they rupture some of the escaping blood may penetrate to the skin surface producing bruise-like markings (Figure 9B). Note how petechiae map onto the underlying rib structure. Blood contacting the rib periosteum (outer bone surface) will give a false "fracture" message to the bone repair system, calling out osteoclasts to remove bone and initiate the (inappropriate) bone repair process [35]. This may distort ribcage development $(\mathrm{C})$ which actually registers previous intercostal vascular rupture, not rib fracture.

\section{Warning Features in DIDS}

The fundamental difference between DIDS and True SBS is that True SBS involves a normal baby and an abnormal carer, whereas DIDS involves an abnormal baby and a normal, or even temporarily absent, carer. Hence, whereas it is virtually impossible to predict when a True SBS Event will occur, features of DIDS have been observed which suggest that at least some cases might be recognised in the early stages and corrective measures taken.

All four infants had disproportionately large head size and/or growth rate at the time of the Event following which a parent or carer was arrested. This would have been due to sub-suture dura signalling for cranial growth [36] in response to transient brain swelling during vascular dilation and oedema.

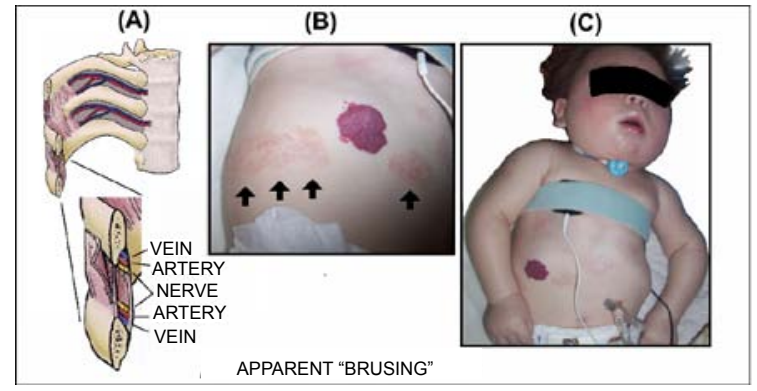

Figure 9: Apparent Thoracic/Abdominal bruising and Rib "fractures". (A) Intercostal Vessel/bone proximity. (B) Manifestations of rib intercostal blood extravasation during transient venous hypertension, arrows. (C) Rib development distortion due to false "repair" stimulation.

\begin{tabular}{|l|l|l|}
\hline FEATURE & DIDS & SBS \\
\hline & $\begin{array}{l}\text { EXPLANATION/ } \\
\text { RELEVANCE }\end{array}$ & $\begin{array}{l}\text { EXPLANATION / } \\
\text { RELEVANCE }\end{array}$ \\
\hline Poor feeding & Pyloric Stenosis & $\begin{array}{l}\text { Observation, causing } \\
\text { carer stress }\end{array}$ \\
\hline Vomiting & Pyloric Stenosis & $\begin{array}{l}\text { Observation, causing } \\
\text { carer stress }\end{array}$ \\
\hline Lethargy & Cerebral oedema & $\begin{array}{l}\text { Observation, causing } \\
\text { carer stress }\end{array}$ \\
\hline Irritability & Cerebral oedema & $\begin{array}{l}\text { Observation, causing } \\
\text { carer stress }\end{array}$ \\
\hline Petechiae & $\begin{array}{l}\text { Capillary bursting during } \\
\text { TCVH }\end{array}$ & N/A \\
\hline Large head & $\begin{array}{l}\text { Skull suture stretch during } \\
\text { TVCH }\end{array}$ & N/A \\
\hline Floppy Head & Excessive cranial weight & N/A \\
\hline Spiking Fevers & $\begin{array}{l}\text { Disabled hypothalamic } \\
\text { temperature limiter }\end{array}$ & N/A \\
\hline Blank Staring Spells & $\begin{array}{l}\text { Disabled axon action } \\
\text { spike transmission }\end{array}$ & N/A \\
\hline
\end{tabular}

Table 1: Pre-Event observations.

They all had periods of extended crying which did not respond to normal comforting procedures. DIDS would suggest pain due to a distended stomach or Mallory-Weiss damage resulting from repeated retching and vomiting. Spiking fevers would suggest oedemous disablement of the temperature regulating centre in the rostral hypothalamus.

Significant features of SBS and DIDS before Events compared in Table 1, and after events in Table 2.

The first four features in Table 1 are identical in both disorders, but petechiae, enlarged and/or floppy heads ( with no evidence of obstructed CSF ducts), and spiking fevers, have not been reported associated with True SBS In the case of K. abnormal cranial growth and petechiae were noticed 14 weeks before the Event. The floppy head, commented on by relatives and friends just before an Event, was another feature of $\mathrm{K}$. and D. and the two previously reported cases [13,12] If any of these symptoms are present in an infant suffering from severe dysphagic symptoms, they should alert one to the possibility of an impending DIDS Event. A search for a cause of excessive venous pressure should be initiated, e.g. pyloric stenosis as in these cases.

\section{Post-Event Features}

Interpretations of post event findings are compared in Table 2 for DIDS and True SBS.

Post Event, both DIDS and True SBS will show retinopathy and subdural haematomas, but in DIDS diffuse intra-parenchymal bleeds may also occur anywhere in the brain. New bleeds may continue to occur with continued loss of brain tissue while in hospital care if further hypertensive events occur. In DIDS cases "rashes" of petechiae on the skin give the appearance of bruising, and that occurring in the peri-anal area will have important legal significance.

\section{Conclusions}

The association of bleeding in the head with preceding dysphagic symptoms, as set out in the 1993 definition of SBS, is a genuine syndrome which requires explanation, but ascribing it uniquely to shaking is an error. An alternative link, examined here, is extreme venous hypertension, generated by compression of abdominal organs during retching and/or vomiting sufficient to rupture head capillaries and veins. 


\begin{tabular}{|l|l|l|}
\hline \multicolumn{1}{|c|}{ FINDING } & \multicolumn{1}{c|}{ DIDS } & \\
\hline Retinopathy & Valsalva Retinopathy / TCVH & Optic Nerve stress during shaking \\
\hline Subdural haematoma & Local bursting of veins at their weakest point in the virtual space below the Dura & $\begin{array}{l}\text { Torn bridging veins resulting from relative brain skull } \\
\text { movement }\end{array}$ \\
\hline Diffuse haematoma & Capillaries can burst anywhere in brain, intra parenchymal bleeds & N/A \\
\hline Cerebral mal-function & Temporary or permanent axon malfunction with changed ionic concentrations & Rupture of brain structure and blood supply \\
\hline Peri-Anal redness & Petichiae in perianal skin normally drained into subcutaneous muscle veins & N / A \\
\hline Unexplained "bruises" & Extravased blood (petechiae) & Imposed trauma \\
\hline
\end{tabular}

Table 2: Post-Event features.

DIDS is an infantile form of the adult Transient Global Amnesia (TGA) disorder, taking place in an infant "elastic " skull where the Monroe-Kelly doctrine does not apply. Both DIDS and TGA result from involuntary Valsalva maneuvers which cause excessive venous hypertension but in the adult TGA venous/capillary dilation is opposed immediately by rise in intracranial pressure, protecting capillaries and veins from excessive distension. The infant skull will "give way" allowing venous/capillary. Thus whereas in both forms local edema may result from water expressed through capillary walls, in DIDS these walls will also be transiently stretched

Pyloric Stenosis develops if there is asynchrony between pyloric wall growth in thickness and circumference. An example was shown of spontaneous resolution of a period of general growth retardation, which recurred later with severe intracranial damage.

Consideration of the mechanics of DIDS suggests that retching may play an important venous hypertensive role before excessive vomiting draws attention to stenosis Further research using some form of strain gage recording system might reveal a pattern identifying it in the presence of other movement artifacts.

This study has revealed that in DIDS, symptoms such as macroencephaly, petechiae, blank staring, and spiking fevers may give warning of impending injurious events, Table 1 . If they are observed in the presence of unexplained retching or vomiting, investigation of the pylorus is indicated, or at post mortem they may used to distinguish between shaking for which the carer is responsible and DIDS where the carer does not even have to be present.

These cases demonstrate the importance of awareness of the Policy Statement issued by American Academy of Pediatrics in 2009 [37]. This draws attention to the necessity to recognize medical conditions that can mimic Abusive Head Trauma (AHT). It lays responsibility on pediatricians to consider alternative hypotheses when presented with findings suggestive of AHT. The hypothesis presented here is one such hypothesis.

\section{References}

1. (1993) American Academy of Pediatrics Committee on Child Abuse and Neglect: Shaken Baby Syndrome: inflicted Cerebral Trauma. Pediatrics 92: 872-875.

2. Annon (1956) The neuromuscular anatomy and physiology of the pylorus. Acta Paediatrica 45: 14-18.

3. Millen JW (1944) The Pyloric Canal. Ulster Med J 13: 156-162.

4. Romer AS, Parsons TS (1977) Digestive System. In: Romer AS, Parsons TS editors. The Vertebrate Body. (5thedn), Philadelphia.

5. Moore KL, Dalley AF (2006) Abdomen (Pyloric Stenosis ). Clinically Oriented Anatomy. (5thedn), Philadelphia.

6. Demian M, Nguyen S, Emil S (2009) Early pyloric stenosis: a case control study. Pediatr Surg Int 25: 1053-1057.
7. Morse SI (1979) Whooping cough (Pertussis). In: Beeson PB, McDermott W Wyngaarden JB, editors. Textbook of Medicine. (15thedn), Philadelphia.

8. McKendrick GDW (1978) Bordetella infections;Whooping cough. In: Scott RB, editor. Price's Textbook of the Practice of Medicine. (12thedn), Oxford: Oxford University Press.

9. Mattle HP, Nirkko AC, Baumgartner RW, Sturzenegger M (1995) Transien cerebral circulatory arrest coincides with fainting in cough syncope. Neurology 45: 498-501.

10. Hinchey J, Chaves C, Appignani B, Breen J, Pao L, et al. (1996) A reversible posterior leukoencephalopathy syndrome. N Engl J Med 334: 494-500.

11. Geddes JF, Talbert DG (2006) Paroxysmal coughing,subdural and retina bleeding: a computer modelling approach. Neuropathol Appl Neurobiol 32: 625-634.

12. Talbert DG (2008) Cyclic vomiting syndrome: Contribution to dysphagic infant death. Med Hypotheses 73: 473-478.

13. Talbert DG (2006) Dysphagia as a risk factor for sudden unexplained death in infancy. Med Hypotheses 67: 786-791.

14. Fisher J, Vaghaiwalla F, Tsitlik J, Levin H, Brinker J, et al. (1982) Determinants and clinical significance of jugular venous valve competence. Circulation 65 188-196.

15. Dugdale D, Longstreth G (2008) Mallory-Weiss tear. www.nlm.nih.gov/ medlineplus/ency/article/000269.htm

16. Schreiber SJ, Doepp F, Klingebiel R, Valdueza JM (2005) Internal jugular vein valve incompetence and intracranial venous anatomy in transient global amnesia. J Neurol Neurosurg Psychiatry 76: 509-513.

17. Nedelmann M, Eicke B.M, Dieterich M (2005) Increased incidence of jugula valve insufficiency in patients with transient global amnesia. J Neurol 252 1482-1486.

18. Mokri B (2001) The Monro-Kellie hypothesis: application in CSF volume depletion. Neurology 56: 1746-1748.

19. Sircar S (2008) Resting Membrane Potential. In: Sircar S, editor. Principles of medical physiology. (1stedn) Stuttgart.

20. Sircar S (2008) Membrane excitation and action potential. In: Sircar S, editor Principles of medical physiology. (1stedn) Stuttgart.

21. Ganong WF (1987) Central regulation of visceral function. In: Ganong WF editor. Review of medical physiology. (13thedn) Connecticut: Prentice-Hal International Inc.

22. Gibson L (2010) Petechiae. Mayo Clinic Online Source.

23. Ely SF, Hirsch CS (2000) Asphyxial deaths and petechiae: a review. J Forensic Sci 45: 1274-1277.

24. West JB, Tsukimoto K, Matheu-Costello O, Prediletto R (1991) Stress failure in pulmonary capillaries. J Appl Physiol 70: 1731-1742.

25. (2010) Wikipedia Petechiae. Online Source.

26. Ganong WF (1987) Dynamics of blood \& lymph flow. In: Ganong WF, editor. Review of medical physiology. (13thedn) Connecticut: Prentice-Hall International Inc.

27. Opperman LA (2000) Cranial sutures as intramembranous bone growth sites Dev Dyn 219: 472-4785. 
Citation: David G Talbert (2011) Pyloric Stenosis as Cause of a Venous Hypertensive Syndrome Mimicing True Shaken Baby Syndrome. J Trauma Treat 1:102. doi:10.4172/2167-1222.1000102

Page 10 of 10

28. Ogle RC, Tholpady SS, McGlynn KA, Ogle RA (2004) Regulation of cranial suture morphogenesis. Cells Tissues Organs 176: 54-66.

29. Tholpady SS, Freyman T, Chadchra D, Ogle R (2007) Tensional forces influence gene expression and suteral state of rat calvariae in vitro. Plast Reconstr Surg 120: 612-613.

30. Mather SJ (1996) Acute airway problems. In: Mather SJ, Hughes DG, editors. A Handbook of Paediatric Anaesthesia. (2ndedn), Oxford: Oxford University Press.

31. Warwick R, Williams PL (1973) Splanchnology(anodermis and sphincters). In: Warwick R, Williams PL, editors. Gray's Anatomy. (35thedn), Edinburgh: Longmans.

32. Moore KL, Dalley AF (2006) Pelvis and Perineum (Anal Canal). In: Moore KL, Dalley AF, editors. Clinically Orientated Anatomy. (5thedn), Philadelphia.
33. Scharli A F, Sieber WK (1969) Surgical approach for the Ramsteadt procedure in hypertrophic pyloricstenosis. Surg Gynecol Obstet 128: 355-357.

34. Okorie N, Dickson J, Carver R, Steiner G (1988) What happens to the pylorus after pyloromyotomy? Arch Dis Child 63: 1339-1340.

35. Talbert DG (2010) Beads but no collar; the significance of an asymptomatc rib rib healing pattern in infants. Med Hypotheses 75: 82-84.

36. Yu JC, McClintock JS, Gannon F, Gao XX, Mobasser J, et al. (1997) Regiona differences of dura osteo induction; squamous dura induces osteogenesis, sutural dura induces chondrogenesis and osteogenesis. Plast Reconstr Surg 100: 23-31.

37. Christian CW, Block R (2009) Abusive head trauma in infants and children Pediatrics 123: 1409-1411. 